\title{
Legacy and Impacts of the Computer Interchange of Museum Information (CIMI)
}

\author{
박물관메타데이터 표준프레임워크 CIMI가 남긴 유산과 영향력 \\ Robbie A. Marshall * \\ Hyuk-Jin Lee **
}

\begin{abstract}
The Computer Interchange of Museum Information (CIMI), operating from 1990-2003, was charged with creating and introducing the international museum community to the concept of adopting metadata industry standards. The CIMI consortium exceeded its original mission by; creating a standards framework, profile, testbeds, important metadata publications, free downloadable metadata software and protocols, and providing instrumental guidance and support in development of new projects. However, CIM's emphasis on the importance and utility of a standards-based approach and the necessity for implementing the CIMI Standards Framework is probably its most important achievement. During CIM's tenure, museums reaped the benefits by learning how to apply the model and standards to meet their individual needs while not having to invent new ones or bear the cost of software development. Although CIMI operations ceased in 2003, its impacts on museum related metadata application and research were unprecedented in that it provided the standards prototype and foundations on which to build. This paper discusses what CIMI bequeathed to the next generation of museum metadata field developers and describes the anticipated realm of future projects and advancement.
\end{abstract}

\section{초 록}

1990년부터 2003년까지 운용된, Computer Interchange of Museum Information (CIMI)는 국제 박물관 사회에 메타데이터 산업표준 채택의 개념을 고안해내고, 소개하는 역할을 했다. CIMI 컨소시엄은 이러한 기본임무를 넘어서, 표준구조 (Standard Framework), 프로파일, 테스트베드 (testbeds), 주요 메타데이터 저작물, 다운로드가능 무료 메타데이터 소프트웨어나 프로토콜등을 생산했고, 새로운 프로젝트에 대한 산업적 안내 및 지원을 제공했다. 하지만, CIMI의 가장 중요한 성취물은 아마도 표준기반 접근의 중요성과 유용성과 CIMI 표준 프레임워크의 실행의 필요성에 대한 강조일 것이다. 이로 인해CIMI의 가동기간동안, 박물관들은 각자의 요구를 충족시키기 위해 새로운 표준/모델의 고안이나 소프트웨어의 개발에 따른 비용부담없이, 메타데이터 모델 혹은 표준의 이용법을 습득하는 것으로 각자의 이득을 거둬 들일 수 있었다. 비록 CIMI의 가동은 2003년으로 중단되었지만, 박물관 관련 메타데이터 응용과 연구에 미친 유산과 영향력은 막대하다고 할 수 있다. 본 논문은 CIMI가 박물관 메타데이터 분야 다음 세대 개발자들에게 남긴 유산을 살펴보고 예상되는 후속프로젝트및 연구를 살펴본다.

Keywords: Computer Interchange of Museum Information (CIMI), Museum metadata frameworks, Metadata profiles, Cultural heritage information

Computer Interchange of Museum Information (CIMI), 박물관 메타데이터 프레임워크, 메타데이터 프로파일, 문화유산정보

* Texas Woman's University, School of Library and Information Studies, Denton, Texas, U.S.A. (RMarshall@mail.twu.edu)

** Texas Woman's University, School of Library and Information Studies, Denton, Texas, U.S.A. (hlee@mail.twu.edu)

- Received : 15 May 2009 - Revised : 22 May 2009 - Accepted : 2 June 2009

- Journal of the Korean Society for Information Management, 26(2): 83-103, 2009.

[DOI:10.3743/KOSIM. 2009.26.2.083] 


\section{Introduction}

Long before the invention of computers, museums exchanged information with each other and their researchers. The introduction of computers has made the practice easier in terms of efficiency but harder due to the complexity of communication among institutions. The prospect of computers supporting exchange of information among museums and construction of shared catalogues motivated the formation of the Museum Computer Network (MCN) in the U.S. in 1967 and continues to be the foundation for many collaborative projects.

The Consortium for Computer Interchange of Museum Information (CIMI) began as an international organization determined to bring museum information to the largest possible audience. Its members consisted of museums, systems vendors, governmental and non - governmental organizations and shared a mission to encourage an open standards - based approach to the management and delivery of digital museum information. Exchange of information among institutions was not the only reason for interchange standards. Formed in 1990, CIMI made substantial progress in researching, developing, and promoting standards for structuring data and for enabling widespread search and retrieval capabilities for the museum community (Miller, Paul, and Grant 2000). Since then CIMI's work was reflected in collaborative demonstration projects that involved the cultural heritage community, and helped them understand how complex museum information can be standardized and made accessible electronically.

\section{Issues of Museum Information Access and Exchange}

Museums acquire their artifacts with associated machine readable data with them from site surveys or auction records. They must incorporate this information and biographical and historical files into their information systems. Computerized documentation that museums assemble around their collections will need to be accessible and meaningful in the future. Data must be transportable from one vendor's system to another, because of system obsolescence and because multiple applications within the museum require access to the same information. Museums also require the ability to deliver information from a variety of sources and formats including print, oral history, still and moving pictures representative of their holdings, and to document the contexts of an object's origin and use. They need to publish their findings and holdings in exhibitions, reference works, print and multimedia, and distribute information electronically. These needs depend on information interchange.

It is difficult to establish the smooth, transparent interchange of information however, because: different brands and types of computers and software are not designed to communicate, different positions within the museum have their own intellectual perspectives, and different processes within the museum require information in different forms. 
Consequently, formatting and content of information in different computer applications varies considerably (Bearman and Perkins 1993). Dunn (2000) and Patel et al. (2005) also explain that many museums wish to provide Internet access to their collections databases. However, the content of museums' collections databases is invisible to search engines and it is impractical to create a webpage for each item in the database. Hence one of the main reasons for creating collection-level descriptions is to facilitate resource discovery of object-level information held within museum databases. Unless the contents of databases are described on the Internet at the collection level, users will not be able to find the data via a Web search. As an example of such an effort to provide Internet access to the object level of a museum, the website of the Metropolitan Museum of Art1) provides the access to a large collection.

Collection-level descriptions can be also used to find a general class of items, such as "Impressionist" even though the museum website contains only references to specific instances of that class, such as "Monet." Suitable terms can be added to the collection-level description to not only ensure that the museum website is located, with both broad or specific terminology, but it is also possible to use collection-level descriptions for resource discovery within distributed resources. Typically, a researcher would not be able to see the relationship between collections of different institutions, for example, library books and museum artifacts, unless there were collection-level descriptions for each. Thus, collection-level descriptions facilitate cross-disciplinary, multi-level access to Web and database resources for a diverse audience. Another important attribute of collection-level descriptions such as; descriptions of a collection, virtual exhibit, or professional resource is that they can be deposited in a central location (e.g., a subject gateway or search engine) to be searched by users. Although there are still challenges to be faced in using collection-level description to facilitate museum resource discovery on the Internet, the CIMI Consortium made important advancements in the field of standards for museum resource description. It is important that museums, libraries, and archival communities work together to ensure that these developments lead to true interoperability and resource sharing on a global level (Dunn 2000). The development of these standards for the creation, processing and encoding of metadata is a vital step toward the goal of achieving cross-domain interoperability. ${ }^{2}$ )

\section{History of CIMI}

In 1986 the International Council on Museums Committee on Documentation (CIDOC) endorsed the standard ISO 2709 as the basis for all museum

1) www.metmuseum.org/collections/index.asp

2) According to Patel et al. (2005), interoperability has been considered at two levels; in terms of internal data exchange and in terms of openness of the system in communication with other external systems. 
information interchange. The CIMI initiative was proposed to the Board of $\mathrm{MCN}$ in 1988 to bring the CIDOC action forward as it fit the new mission of increasing the role of computers in museum management and collection documentation through promotion of standards. In endorsing the CIMI initiative, the Board of MCN acknowledged that the absence of standards significantly inhibited the use of automation by museums and the creation of museum products by vendors. In 1989 MCN issued invitations to U.S. museum associations to send representatives to serve on the CIMI Committee. The committee represented most of the museums in the country along with: the U.K. Museum Documentation Standard project, the chairman of CIDOC, and some active observers. It was anticipated that the effort would lead directly to adoption of a format for interchange based on the MARC format, known as ISO 2709. However, MCN noted that there were problems in using ISO 2709 (which had been designed for text only), and suggested that either it be modified or an alternative format be devised.

It became apparent to the CIMI committee in 1990 that museum data and interchange services had evolved considerably since 1986. CIMI realized that digital image bases, sound bases, compound digital multi-sensory, and multi-media documents would have a significant role in collections documentation and services other than collections information database construction. Exhibits devel- opment and loan, photo fulfillment, and conservation assessment would be a focus for data interchange in future museum networks. CIMI focused on establishing a process for the involvement of the museum community to define requirements for museum information interchange. Therefore, the Committee created a statement of mission and guiding principles for conducting its work, shown in Appendix A (Bearman and Perkins 1993).

\section{Description of CIMI}

According to Alice Grant, CIMI XML project leader, "The CIMI Schema enables museums to encode rich descriptive information relating to museum objects, including associated information about people, places and events surrounding the history of museum objects, as well as information about their management and use within museums" (Grant 2002, p. 2). CIMI uses both SGML and XML for structuring information and uses ANSI/NISO standard Z39.50, American National Standard protocol for information retrieval for search and retrieval. The CIMI Profile includes a CIMI Attribute Set, which enables the expressions of queries for searching cultural heritage museum information resources. The Profile uses the Z39.50 Generic Record Syntax (GRS) for packaging retrieved records for presentation to the client (Grant 2002).3) To overcome semantic and schematic dis-

3) Z39.50 is a client-server protocol widely used in library environments; digital libraries, museums, and incorporated into integrated library systems, for searching and retrieving information spread over a number 
crepancies among the various data sources the protocol relies on a world view of information as a flat list of fields, called Access Points (AP). It is covered by ANSI/NISO standard Z39.50, and ISO standard 23950. The standard's maintenance agency is the Library of Congress.

\subsection{Designation and encoding}

CIMI uses SGML (Standardized General Markup Language) as well as standards like Z39.50. SGML is used to express the structure and content of exhibition catalogues and as the foundation for a data interchange format for collections records. CIMI uses the standard features of the TEI Header to encode core bibliographic information about each document, including access and copyright information (CIMI 2002). CIMI developed a comprehensive set of museum DTDs (Document Type Definitions), one for each genre of museum information, rather than one generalized DTD for all museum information. It was decided that the DTD should allow for all the significant features of the source document to be marked up. The first type of information to be analyzed was exhibition catalogues (as a test case for any text-based museum information resources). The following is based on the DTD for this type of information.

Basic descriptive elements:

- Record Summary

- Dates

of heterogeneous sources.
- Object Title Name

- Document Title

- Editor

- Person Name

- Organization Name

- Place

- Record type

Subject description:

- Classification

- Concept

- Event

- Material

- Mark

- Object

- Object Identifier

- Occupation

- Role

- Style/Movement

- Subject

- Topic

URIs:

- Not defined.

Resource format and technical characteristics:

- Not defined.

Host administrative details:

- Organization Name

- Place 
Administrative metadata:

- Record Type

- Document Source

- Contributor

- SGML Source File Name

- Document No.

Provenance/source:

- Document Source

Terms of availability/copyright:

- Copyright

\subsection{Rules for the construction of CIMl elements}

The CIMI Standard Framework can be implemented at two levels. The first is specification of hardware and software so that it supports the standards defined in the CIMI Standards Framework. This ensures that the data can be interchanged even if the entire institutional context cannot be. The second level addresses the standardization of data content (the fields of information), and data values (what is input in the fields) (UKOLN Metadata Group 1998).

\section{Sample CIMI meta-record}

The CIMI access point mechanism is designed to be very flexible. By providing simple "building blocks", the CIMI framework allows complex statements to be built up as required. This meta-record describes an object entitled "Storm-tossed Frigate", giving its artist, date of creation and current identity number (Burnard and Light 1996):

$<$ topic access-point="object.work"

value $=$ "Storm-tossed

Frigate">

$<$ context $\mathrm{CHIO}=$ "creation" $>$

$<$ context $\mathrm{CHIO}=$ "creator" $>$

$<$ topic access-point="person" value="Chambers,

Thomas" ROLE="artist">

$</$ context $>$

$<$ topic access-point="date-range" FROM="1825"

$\mathrm{TO}=" 1874 "$ EXACT="NONE">

$</$ topic $>$

$</$ context $>$

$<$ context $\mathrm{CHIO}=$ "current-location" $>$

$<$ topic access=point="identity-number"

value $=" 1969.11 .1 "></$ topic $>$

$</$ context $>$

$</$ topic $>$

This set of data would typically be placed just inside a section of the text which describes that object, and so would associate the following index terms with that section as explained in Table 1.

\section{Testing of CIMI}

Phase 1 of the CIMI Dublin Core Testbed Project was undertaken in 1998 with the goal of testing "assumptions related to the flexibility and simplicity of the Dublin Core element set, and its suitability and readiness for deployment." CIMI 
〈Table 1〉Sample CIMI Meta-record

\begin{tabular}{l|l|l}
\hline \multicolumn{1}{c|}{ Access Point } & \multicolumn{1}{|c}{ Value } & \multicolumn{1}{c}{ Context } \\
\hline Object/Work & Storm-Tossed Frigate & \\
\hline Person & Chambers, Thomas & creation - creator ( + role= "artist") \\
\hline Date Range & $1825-1874$ & creation [of object] \\
\hline Identity Number & 1969.11 .1 & current location [of object] \\
\hline
\end{tabular}

members created object-level descriptions using the Dublin Core standard, and identified issues surrounding the functionality of Dublin Core for resource discovery on the Internet. Phase 2 of the Dublin Core Testbed Project included the publication of a "Guide to Best Practice" for museums using Dublin Core, and an "examination of Resource Description Framework" (RDF) as an effective method for enabling interoperability between applications that exchange metadata (Dunn 2000). The testbed firmly established the ability of the Dublin Core to act as a high - level resource - location tool, useful for museum collections. However, the testbed discovered further that Dublin Core Semantic Refinements did not enable retention of integrity of museum information at a detailed level. The CIMI Institute's initial activity intending to raise awareness and cultivate expertise in the community culminated in a successful series of seminars and workshops on the implementation of Dublin Core (Miller, Paul, and Grant 2000).

Moen (1996) also presented the CIMI application of Z39.50. From 1995 to 1997, CIMI explored and applied Z39.50 to enable search and retrieval of cultural heritage resources. Z39.50 servers and clients were implemented as part of the CIMI Z39.50 Interoperability Testbed. The testbed's goal was to test CIMI Profile specifications and demonstrate the capability of Z39.50 to support search and retrieval between multiple implementations of specific types of cultural heritage data: collection management object records with images, images with associated text, and bibliographic records. The implementations used Z39.50 to search and retrieve textual data from testbed servers and Hypertext Transfer Protocol (HTTP) to transfer images between testbed servers and clients. An important concern in the search and retrieval of museum information is handling multiple images and resolutions of images associated with an artifact. Testbed servers presented a Java-based Z39.50 interoperability testing client with an object record describing: the museum artifact, digitized images associated with the object, and resolutions of each image. CIMI's testbed demonstrated that the Z39.50 client/server implementations could be used with existing museum systems and databases of cultural heritage information resources to present new capabilities in locating networked resources as well as performing precise and selective searching across servers. A user could enter a single query to search the testbed servers and results from each server would be obtained. Semantic interoperability between these distributed resources through Z39.50 
allows users the ability to conduct specific searches on access points related to museum information such as object title, artist name, material, and provenance and elicit meaningful results. Most importantly, the testbed provided various implementers with an opportunity to gain experience with Z39.50 and the CIMI Profile.

Thus, CIMI's application of Z39.50 in the networked cultural heritage information environment broke new ground in distributed and integrated access to text and non-text digital collections per the CIMI Profile: Z39.50 Application Profile for Cultural Heritage Information (Moen 1996).

As a response to the challenge of providing access to museum resources on the Web, according to Perkins (2001), CIMI worked with the OAI (Open Archives Initiative) as an alpha tester of OAI, building on CIMI's public access capabilities and past testbed facilities.

\section{Related Projects}

Interoperability testbed participants continued to address issues related to metadata, semantic interoperability, expansion of the CIMI Profile to handle other types of cultural heritage information resources, and evolution of the CIMI Z39.50 specifications (Moen 1996). One such project was the European Community's Aquarelle Project, whose aim was validating and demonstrating standards supporting cultural documentation exchange. Participants in Aquarelle based their work on the Draft version 3 of the CIMI Profile, a companion profile to the Digital Collections profile. As well as identifying the access points, it defined them as both Z39.50 USE attributes and SGML tags. Another goal was interoperability of Aquarelle clients and CIMI servers and vice versa. Most of the extensions fall into two categories: first, support for the Aquarelle architecture (with the Access Server and emphasis on SGML documents); and second, the extension from CIMI's emphasis on museum information to include more diverse forms of cultural heritage, such as architecture. Where the Aquarelle Profile's extensions to the CIMI Profile had wider application outside the bounds of the Aquarelle project, it was thought that they could be absorbed into a future version of the CIMI Profile, so that there would eventually be a single profile shared by both projects (Michard et al. 1998).

Other projects involved in the pioneering development of a museum profile for use with the Z39.50 protocol for distributed access to databases, include Project CHIO (Cultural Heritage Information Online) and the development of an SGML DTD for the online delivery of rich - text information such as exhibition catalogues. Additionally, projects such as the evaluation of integrated information management methodologies in museums have brought direct benefits to its members and the museum community. Most notably, they include working with the MDA (Museum Documentation Association) to establish an XML-DTD for SPECTRUM, (Standard ProcEdures for CollecTions Recording Used in Museums), the UK Museum Documentation 
Standard. Benefits of this work include the elimination of costly and time consuming delays experienced by museums and vendors when migrating data between systems. An XML-DTD for museum information permits easier integration of information across diverse systems being used in single organizations (Miller, Paul, and Grant 2000).

\subsection{Scope of the CIMl XML Schema for SPECTRUM}

The scope and content of version 1.5 of the CIMI XML Schema for SPECTRUM provides examples of and instructions on the use of the Schema during the Alpha Test Period following the public release in October 2003. The CIMI Schema for SPECTRUM: The UK Museum Documentation Standard enables the XML encoding of individual items in museum collections. SPECTRUM was developed and tested within CIMI's XML Working Group. The CIMI XML testbed succeeded in its aim to demonstrate the potential of the CIMI Schema to encode data from a wide range of museum collections. The CIMI Schema is extremely broad in scope and it was unrealistic to expect data from one institution to utilize all areas of the Schema. One aim of the Alpha Test Period was to explore areas of the schema which are not possible to test within a relatively small user community. The example of a dataset encoded using Schema version 1.5 is in Appendix B (Grant 2002).

\subsection{Other applications}

According to Miller, Paul, and Grant (2000), the CIMI Handscape project's (Handheld Access to the Museum Landscape) goals were to explore the possibilities of extracting detailed descriptions from repositories and packaging them for delivery over a multitude of channels and to a variety of audiences. The project was funded by Intel Corporation in 2001 to experiment with the design, uses and evaluation of mobile guides in museums. Cornell's Human Computer Interaction Group was involved in the effort as evaluators of existing handheld tour guides. During the evaluations, it became apparent that the data collected through interviews and surveys could be supplemented with data collected through the use of the handhelds themselves. By incorporating tracking functionality into the handhelds, they could analyze levels of popularity for different objects and information, tempo of movement and information consumption, and physical navigation paths. This information could also be available more immediately rather than waiting for the researchers to conclude an analysis. According to Gay and Boehner (2005), this dynamic feedback information would be not only useful for curators and museum designers in order to maximize the interest and value of the exhibits, but the information might also be of interest to visitors themselves. 


\section{Discussion}

CIMI's work demonstrates how existing and emerging standards, such as Z39.50 and the Dublin Core Metadata Element Set, address major interoperability barriers between heterogeneous information systems for users attempting distributed search and retrieval in the networked environment. Another important aspect of the CIMI schema, besides interoperability, is its flexibility. As demonstrated, this schema can be used with other schemes or embedded within documents. CIMI offers the possibility of an extremely rich set of metadata; far beyond Dublin Core. There are very few mandatory elements required, although CIMI, designed for art and historical museum applications is tightly customized.

When CIMI migrated from the Dublin Core to intra community data exchange based on XML, it showed that the CIMI Z39.50 Profile could be used as a basis for distributed applications using HTTP technology such as a record schema (DTD/ XML-schema) access points and semantics (Drenth 2000). Not only did CIMI's use of Z39.50 reach essential first milestones for distributed search and retrieval, but the CIMI Z39.50 specifications continued to evolve to address important museum concerns such as intellectual property protection and access control to their resources. Consequently, the CIMI Profile expanded to handle other types of cultural heritage information resources as well as influencing and collaborating with initiatives like the Bath Profile and the ABC Ontology and
Model. The ABC Metadata Model was effectively applied to descriptions of complicated objects provided by the CIMI museums and libraries.

Some areas of museum records can be particularly complex to handle. SPECTRUM effectively responded to issues raised during the CIMI schema development phase, and became the basis for the next generation of museum collection description standards. The revised SPECTRUM XML schema is designed to help museums and other cultural organizations exchange information about their collections. It is based on the SPECTRUM 3.1 standard, published in March 2007 and was developed by MDA in partnership with leading sector expert Richard Light. SPECTRUM XML Schema 3.1 replaces the v1.5 schema published by CIMI (Consortium for the Computer Interchange of Museum Information) in 2002.

It now:

- Provides a standard format for exchanging object records between different collections management systems;

- Supports the management of rights associated with objects;

- Allows for the exchange of user generated interpretation based on the Revisiting Collections methodology (Collections Trust, 2008).

According to Patel (2005), with regard to operation in the Web environment, the ARCO Metadata Element Set (AMS) is one of the latest iterations of museum metadata schema, following in CIMI 
and SPECTRUM's footsteps. AMS is designed to take advantage of the CIDOC CRM (Conceptual Reference Model), which is emerging as an important set of specifications for the cultural heritage domain. The CRM needs to be supplemented with application-level detail; in the case of the AMS, this role is served by SPECTRUM. A mapping of SPECTRUM to the CRM is already in existence and forms the basis for integrating disparate information from the museum, library and archive communities. The goal of the Augmented Representation of Cultural Objects (ARCO) system is to develop innovative technologies and expertise to help museums create, manipulate, manage and present small to medium artifacts in virtual exhibitions both within museum environments and over the Web. Although many museums have established an online presence, currently this presence is mostly 2-dimensional. ARCO seeks to enhance the experience of cultural objects on the Web by providing technologies for creating 3D digital representations of artifacts and allowing users to interact with them. Table 2 summarizes and shows the timetable of museum related metadata development.

〈Table 2〉 Timetable of Museum Metadata Standards Development/Projects

\begin{tabular}{c|l}
\hline Year & \multicolumn{1}{|c}{ Event } \\
\hline 1967 & Formation of Museum Computer Network \\
\hline 1970 's & CHIN Canadian Heritage Information Network Data directories (mapable to SPECTRUM) \\
\hline 1986 & MSN CIDOC Endorsed ISO 2709 for Museum Information Interchange \\
\hline 1988 & CIMI Initiative Proposed \\
\hline 1990 & Formation of CIMI \\
\hline 1995 & CIMI explored and applied Z39.50 to enable search and retrieval of cultural heritage resources \\
\hline 1995 & CIDOC Guidelines for Museum Data Categories released \\
\hline $1995-1998$ & $\begin{array}{l}\text { Project CHIO (Cultural Heritage Information Online) incorporates CHIO demonstrator, CIMI Profile } \\
\text { and Z39.50 protocol for search and retrieval of museum data }\end{array}$ \\
\hline 1998 & CIMI Dublin Core Testbed Project \\
\hline 1998 & Aquarelle Profile's extensions applied to the CIMI Profile \\
\hline 1998 & SCRAN Metadata Repository Launched \\
\hline 1999 & CIMI Guide to Best Practice: Dublin Core \\
\hline 2000 & CIMI's test of OAI \\
\hline 2000 & VRA (Visual Resources Association) Data Standards Committee defined VRA Core Categories \\
\hline 2000 & Development of XML-DTD via SPECTRUM \\
\hline 2001 & Bath Profile \\
\hline 2001 & ABC Ontology Model \\
\hline $2001-2004$ & Intel Handscape Project \\
\hline 2001 & OKI Launched \\
\hline 2002 & AMICO (Art Museum Image Consortium) Data Specifications released \\
\hline 2003 & RIT’s Visualizing Cultures: Image Driven Scholarship launched \\
\hline
\end{tabular}




\begin{tabular}{l|l}
\hline 2004 & ARCO Metadata Element Set \\
\hline 2006 & OAICatMuseum software for descriptions of collection items \\
\hline 2008 & COBOAT metadata publishing tool released \\
\hline 2008 & OKI II Launched \\
\hline 2008 & DARIAH preparation begins \\
\hline 2009 & OCLC Museum Data Exchange Project \\
\hline 2009 & ADS online releases of excavation sites \\
\hline
\end{tabular}

\section{Conclusion and Future Work}

The Consortium for Interchange of Museum Information discontinued its operations as of December 15, 2003. The Executive Committee announced that it was a difficult but unavoidable decision after more than a year of searching for additional resources upon which to build a meaningful program.4) Despite the closure, CIMI continued to make its intellectual assets available to the community through its website.

Originally the Consortium for the Computer Interchange of Museum Information, CIMI, was formed to support the development and dissemination of community standards for preserving museum information in digital form. CIMI and its supporters created important intellectual assets, from publications of standards to the Dublin Core Best Practice manual. In the 1990s CIMI guided museums on information interchange, published the CIMI Standards Framework, endorsed SGML for structuring information and Z39.50 for search and retrieval, and developed a standard for finding aids. CIMI's Project CHIO (Cultural Heritage Information Online) provided a way to test SGML and Z39.50 as standards. A further case study tested CIMI's standards-based information strategies in the "real world" of eight museums. Projects from 2000 through 2003 explored the nature of museum information and ways to involve information resources in museum visitors' experiences; contributed to the development of the SPECTRUM Document Type Description; and investigated ways to incorporate handheld, wireless, mobile "computing" into museum visitors' experience in the Handscape project. Although CIMI operations ceased at the end of 2003, the three-year Handscape project continued until June 2004. CIMI provided a stepping stone via SPECTRUM to the digital representation of museum artifacts. CIMI's experience with metadata harvesting allowed for the exploration of the OAI Protocol as an enabling technology to facilitate access to resources by making it easier for museums to expose and collect metadata. In addition, CIMI recommended sustained testing of the OAI protocol in order to make rich museum information and resources more widely available

4) http://www.dlib.org/dlib/january04/01inbrief.html 
to researchers and other users. The RLG (Research Library Group), which is now a part of OCLC, is continuing the tradition of museum data exchange through the use of the OAI-PMH (Open Archives Initiative Protocol for Metadata Harvesting) which was recognized by CIMI as being able to significantly enhance museum data access. Much of CIMI's work has been taken up by museum system vendors and other organizations.

Although the CIMI initiative is now defunct, it left its legacy not only in the SPECTRUM schema, available for download at Collections Trust http://www.mda.org.uk/schema (2008), and the OAI metadata harvesting facility, but in its cooperative efforts within and without the museum community, Dublin Core Best Practice Manual, development of testbeds, enhancement of the physical museum experience, exploration of metadata and framework combinations, and advancement of cultural heritage resource description, storage, and retrieval. After bringing the concept, structure, and function of the CIMI Standards to the museum community, a critical aspect of the program was the continued technical support the CIMI consortium provided as well as the involvement in many emerging metadata related applications and activities. The CIMI Standards Framework as a flexible model (in the context of how to develop standards) provided a secure foundation for the future in the complex field of museum data interchange.

The mantle of the future for digital museum object description, exchange, and access has been taken up by RLG, OAI, SPECTRUM, ARCO, SCRAN, and JISC (to name a few) in their efforts to build on CIMI and create more sophisticated tools for collection management, digital preservation, and the development of collaborative cultural heritage repositories. JISC (the Joint Information Systems Committee) using SPECTRUM-XML along with OAI and other technologies has helped launched ADS (Archaeology Data Service).5) ADS supports: the deployment of digital technologies, research, preservation, and learning and teaching with digital resources. Researchers can explore their interactive maps and database of museum collecting areas. A learning initiative that incorporates over 360,000 images, movies, and sounds, serves 4,000 institutions, collaborates with 300 cultural institutions in the UK and is part of the Royal Commission on the Ancient and Historical Monuments of Scotland is known as SCRAN (Scottish Cultural Resources Access Network). SCRAN was also involved in the funding of cultural collection digitalizing for educational purposes and the website now achieves 1 million visits per day. An ambitious project that embodies the ideal of the cultural heritage repository is called DARIAH (Digital Research Infrastructure for the Arts and Humanities). DARIAH's mission is to facilitate long-term access to all European arts and humanities data for the purposes of research. Its digital research infrastructure will connect scholarly data archives and repositories with cultural

5) http://ads.ahds.ac.uk 
heritage for the arts and humanities across Europe.6) This project takes the digital repository a step further in that it plans to integrate user interfacing tools to support e-research and e-learning activities. DARIAH has coined the phrase "e-humanities", and intends to provide additional services to analyze, annotate, and share arts and humanities research activities along with best practices for digitization and metadata standards.

Some other exciting new projects are incorporating technology that will: examine large bodies of previously inaccessible images, compose original texts with unlimited numbers of full-color, highresolution images, and discover innovative ways of analyzing and presenting images. In an interesting study, Lewis, Hastings, and Hartman (2004) discuss the issues related to the development of standardized metadata schema for 3D images by using the existing metadata schema for still images as a starting point. Investigation and development of standardized metadata schema for 3D images would not only be beneficial to the virtual reality community such as Second Life ${ }^{7)}$ but also to the traditional museums. Many museums initiate and conduct the digital archiving projects for cultural heritage, where 3D scanning technology is one of important components. Therefore, the development of 3D standard metadata schema is a timely topic to pursue.

Finally, collaborative efforts like the Open Knowledge Initiative (OKI 2008) continue to proliferate and evolve even as new concepts are introduced such as "e-research" and the "MetaMuseum.” The Meta-Museum blends virtual reality and artificial intelligence technologies with conventional museums to maximize the exploration of a museum's archives and knowledge base and provide an interactive, stimulating and educational experience for visitors. As a future research agenda, we may investigate how the latest software advancements and standards are increasingly inspiring the application of 3-D, animation, and virtual reality/environments to cultural heritage resources and institutions and the results of these innovations.

\section{References}

Archives and Museum Informatics. 2008. "The Meta

Art Museum: Towards the Promise of an Open Collaboration Platform." [online]. [cited: 2009.5.9].
$<$ http://www.archimuse.com/mw2008/pap ers/fleming/fleming.html>.

Bearman, D. and Perkins, J. 1993. "CIMI Consortium for the Computer Interchange of Museum

6) http://www.dariah.eu/

7) http://secondlife.com 
Information. Museum Computer Network.”

[online]. [cited: 2009.3.17].

$<$ http://www.cni.org/pub/CIMI/>.

Burnard, L. and Richard L. 1996. "Three SGML metadata formats: TEI, EAD, and CIMI. A Study for BIBLINK Work Package" 1.1." [online]. [cited: 2009.4.9].

$<$ http://www.ifla.org/documents/libraries/c ataloging/metadata/biblink2.pdf $>$.

Collections Trust. 2008. "Spectrum XLM Schema." [online]. [cited: 2009.3.29]. $<\mathrm{http}$ //www.mda.org.uk/schema $>$.

Consortium for the Computer Interchange of Museum Information (CIMI). 1999. "Guide to Best Practice: Dublin Core (DC $1.0=$ RFC 2413)." [online]. [cited: 2009.3.21]. $<$ http://coombs.anu.edu.au/ cookproj/proj ect/guide/CIMI_bestprac.PDF>.

Cover Pages: Online Resource for markup language technologies. 2002. "Consortium for Interchange of Museum Information (CIMI)." [online]. [cited: 2009.3.24]. $<\mathrm{http}$ //xml.coverpages.org/cimi.html $>$.

Drenth, B. D. 2000. 'It's Distributed Searching, Jim." [online]. [cited: 2009.3.23]. $<$ http://www.loc.gov/z3950/agency/zig/me etings/leuven/presentations/bert.ppt>.

Dunn, H. 2000. “Collection Level Description - the Museum Perspective." D-Lib Magazine [online], 6, no.3. [cited: 2009.5.9]. $<$ http://www.dlib.org/dlib/september00/du nn/09dunn.html>.

Gay, G. and Kirsten B. 2005. "CIMI Handscape
Project Final Report." [online]. [cited: 2009.3.29].

$<$ http://www.hci.cornell.edu/projects/pdfs $\% 20 \mathrm{of} \% 20 \mathrm{pubs} / \mathrm{handscape.pdf}>$.

Grant, A. 2002. "CIMI XML Schema for SPECTRUM: Supporting Documentation of version 1.5." [online]. [cited: 2009.3.25]. $<\mathrm{http} / / / \mathrm{xml}$.coverpages.org/CIMI-Supporti ngDoc15.pdf $>$.

Harvard University Library. 2008. "VIA Metadata Standards Development: VIA \& OLIVIA: Office for Information Systems.” [online]. [cited: 2009.3.27]. $<$ http://hul.harvard.edu/ois/systems/olivia_ via/via_standards.html $>$.

Lagoze, C. and Hunter, J. 2001. "The ABC ontology and model." Journal of Digital Information 2, no. 2 .

Lewis, E., Hastings. S.K., and Hartman, C. 2004. "Recommendations for Metadata Standards for 3D Images on the Web." IS\&T's 2004 Archiving Conference. 2004, April 20. [San Antonio, Texas].

Metropolitan Museum of Art. 2009. [online]. [cited: 2009.4.11]. $<$ http://www.metmuseum.org/Works_Of_ Art/index.asp $>$.

Michard, A. and Christophides, V., Scholl, M., Stapleton, M, Sutcliffe, D., and Vercoustre, A-M. 1998. "The Aquarelle Resource Discovery System.” [online]. [cited: 2009. 3.29].

$<$ http://www.ics.forth.gr/isl/publications/p 
aperlink/Aquarelle_Ressource/html/comne tv2.html>.

Miller, P. and Grant, A. 2000. "Towards the intelligent museum.” Ariadne, [online]. no. 25. [cited: 2009.3.11].

$<$ http://www.ariadne.ac.uk/issue25/cimi/>.

Moen, W. E. 1996. “The CIMI Profile: Z39.50 Application Profile Specifications for Use in Project CHIO Draft Version 3." The CIMI Profile Development Working Group. School of Library and Information Sciences: University of North Texas. [online]. [cited: 2009.4.4].

$<$ http://www.loc.gov/z3950/agency/profile s/cimi2.html\#Attribute>.

Moen, W. E. 1998. “Accessing Distributed Cultural Heritage Information." Communications of the $A C M$, 41, no.4: 45-48.

Moen, W. E. 1998. "CIMI's Z39.50 Interoperability Testbed: Search and Retrieval of Distributed Cultural Heritage Information." Project Manager, CIMI Z39.50 Working Group School of Library and Information Sciences University of North Texas Denton, TX. [online]. [cited: 2009.3.21].

$<$ http://www.unt.edu/wmoen/publications/ CIMI_ACMrev.htm>.

OKI. 2009. “Open Knowledge Initiative.” [online]. [cited: 2009.4.4].

$<\mathrm{http}$ //www.okiproject.org/>.

Patel, M., White, M., Mourkoussis, N., Walczak,
K., Wojciechowski, R. and Chmielewski, J. 2005. "Metadata requirements for digital museum environments." International Journal on Digital Libraries, 5, no.3: 179-192.

Perkins, J. 2001. “A New Way of Making Cultural Information Resources Visible on the Web: Museums and the Open Archive Initiative.” $5^{\text {th }}$ Museums and the Web 2001: Selected Papers from an International Conference. 2001, March 15-17. [Seattle, Washington]. Smiraglia, R. P. 2005. "Content Metadata--An Analysis of Etruscan Artifacts in a Museum of Archeology." Cataloging \& Classification Quarterly, 40, no.3/4: 135-151.

Spinazze, A., Wiley, P. and Gill, T. 2001. "CIMI Consortium--the organization of museum intelligence [Consortium for the Interchange of Museum Information].” International Cataloguing and Bibliographic Control, v.30 no.1: 5-7.

Thomas, J. 1999. "Meaning and Metadata: Managing Information in a Visual Resource Reference Collection.” 1999 ACH-ALLC Conference. [online]. [cited: 2009.3.24]. $<\mathrm{http}: / / \mathrm{www} 2$ iath.virginia.edu/ach-allc.99 /proceedings/thomas.html>.

UKOLN Metadata Group. 1998. “Computer Interchange of Museum information (CIMI)." [online]. [cited: 2009.3.24]. $<$ http://www.ukoln.ac.uk/metadata/desire/ overview/rev_04.htm>. 


\section{Appendix A}

\section{CIMl Mission Statement and Goals}

\section{Mission Statement}

The mission of the Computer Interchange of Museum Information committee is to identify a technical framework to support the computer interchange of all museum information deemed relevant by the museum community.

\section{Goals}

\section{Develop a technical framework}

Develop a technical framework known as the CIMI Standards Framework by combining data interchange formats, interchange transport protocols, transfer media options, and other requirements to coherently support the interchange of museum data.

Assist in the development of museum data interchange formats

Work with task groups from the professional community to map specific requirements into the CIMI Framework by defining standard interchange formats that are tailored to the needs of particular interchanges.

Create support and acceptance

Create the conditions to encourage widespread acceptance of the CIMI Framework by assuring their effectiveness, by communicating extensively with a broad professional community, by working with organizations representing the information needs of the professional community, and by implementing a legitimate decision making process.

\section{Accommodate evolution and maintenance}

Work towards a mechanism to support the maintenance and continued development of the CIMI Protocols in response to the ongoing elaboration of community interchange needs and the evolving technical environment for providing interchange.

\section{Guiding Principles}

Conduct the business of the committee in an open, consultative manner. Fundamental to this is the participation of standards consumers, producers and others with relevant interests; decision making by consensus; the 
opportunity for broad public review of work; and the adoption of other relevant national and international standards.

Work with Task Groups constituted from the professional museum community to ensure that the CIMI Framework neither dictates the content or purpose of interchange, but assures the accommodation of the information needs desired and expressed by the profession.

\section{Appendix B}

\section{Excerpt of CIMI XML Schema Testbed Dataset for SPECTRUM}

$<$ cs:interchange

- <cs:record $>$

$-<$ cs:data $>$

- <cs:object>

- <cs:acquisition>

- <cs:date $>$

- <cs:earliest $>$

$<$ cs:date $>1892</$ cs:date $>$

$</$ cs:earliest $></$ cs:date $>$

$<$ cs:source $>$

- <cs:person>

- <cs:name $>$

$<$ cs:forename $>$ Paul Howard $</$ cs:forename $>$

$<$ cs:surname $>$ MacGillivray $</$ cs:surname $>$

- <cs:associations $>$

- <cs:general-associations $>$

$<$ cs:concept $>$ Birds $</$ cs:concept $>$

$</$ cs:general-associations $>$

$<$ cs:concept $>$ Seabirds $</$ cs:concept $>$

$</$ cs:general-associations $>$

$<$ cs:concept $>$ Sula bassana $</$ cs:concept $>$

$</$ cs:general-associations $>$ 
$<$ cs:concept $>$ Gannet $</$ cs:concept $>$

$</$ cs:general-associations $>$

$<$ cs:concept $>$ Natural History $</$ cs:concept $>$

$</$ cs:general-associations $>$

$<$ cs:concept $>$ Artworks $</$ cs:concept $>$

$</$ cs:general-associations $>$

$<$ cs:concept $>$ Paintings $</$ cs:concept $>$

$<$ cs:association-type $>$ Contributor of data to RLG Cultural Materials $</$ cs:associationtype $>$

- <cs:place $>$

$<$ cs:name $>$ Cromwell Road $</$ cs:name $>$

$<$ cs:nametype $>$ street $</$ cs:nametype $>$

$</$ cs:place $>$

$<$ cs:name $>$ London $</$ cs:name $>$

$<$ cs:nametype $>$ city $</$ cs:nametype $>$

$</$ cs:place $>$

$<$ cs:name $>$ United Kingdom $</$ cs:name $>$

$<$ cs:nametype $>$ country $</$ cs:nametype $>$

$</$ cs:place $>$

$<$ cs:postcode $>$ SW75BD $</$ cs:postcode $>$

$</$ cs:address $>$

$<$ cs:name $>$ Natural History Museum $</$ cs:name $>$

$</$ cs:organisation $>$

$<$ cs:description $>$

- <cs:inscription $>$

$<$ cs:description>Inscription on reverse: "Gannet. Sula alba. Nearly two years old, the adult plumage almost complete. From an individual obtained on the Bass, and lent by W. Stables Esq. Edinburgh, May, 1831.

W.McG" $</$ cs:description>

$</$ cs:inscription $>$

- <cs:material $>$

$<$ cs:keyword $>$ Watercolour on paper $</$ cs:keyword $>$

$</$ cs:material $>$

$</$ cs:description $>$

- <cs:identification> 
$<$ cs:brief-description>Part of the largely unpublished collection of the work of William MacGillivray [1796-1852]. The collection was presented to The Natural History Museum by MacGillivray's son, Paul, in 1892. Pencil and watercolour. Drawn to accompany his 5 volumes on British birds, MacGillivray's paintings are stunning works of art. MacGillivray captures the spirit of the Gannet with his delicate touch, while retaining scientific accuracy. Genus: Sula. Species: bassana. Owner of specimen depicted: William Stables. Specimen captured at: East Lothian, Bass Rock.</cs:brief-description $>$

- <cs:object-name>

$<$ cs:author $>$ Natural History Museum</cs:author $>$

$<$ cs:name $>$ Watercolors $</$ cs:name $>$

$</$ cs:object-name $>$

$<$ cs:object-number $>$ UKHMMacGill001 $<$ cs:objectnumber $>$

- <cs:object-title $>$

$<$ cs:title $>$ Gannet: Sula bassana $</$ cs:title $>$

$</$ cs:object-title $>$

- <cs:date $>$

- <cs:earliest>

$<$ cs:date $>$ May, $1831</$ cs:date $>$

$</$ cs:earliest $>$

$</$ cs:date $>$

- <cs:person>

- <cs:birth>

- <cs:date $>$

- <cs:earliest>

$<$ cs:date $>1796</$ cs:date $>$

- <cs:earliest>

$<$ cs:date $>1851</$ cs:date $>$

- <cs:name $>$

$<$ cs:forename $>$ William $</$ cs:forename $>$

$<$ cs:surname $>$ MacGillivray $</$ cs:surname $>$

$</$ cs:name $>$

- <cs:place $>$

$<$ cs:name $>$ Edinburgh $</$ cs:name $>$

$</$ cs:place $>$ 
$<$ cs:name $>$ Lothian $</$ cs:name $>$

$</$ cs:place $>$

$</$ cs:data $>$

- <cs:metadata $>$

<cs:progress $>$ Mapped and converted from RLG Cultural Materials by Fae Hamilton, RLG, May,

2002. $</$ cs:progress $>$

$</$ cs:metadata $>$

$</$ cs:record $>$

$</$ cs:interchange $>$ 